\title{
Factors associated with utilization of community health workers in improving access to malaria treatment among children in Kenya
}

\author{
James Kisia ${ }^{1}$, Florence Nelima ${ }^{3 *}$, David Odhiambo Otieno ${ }^{1 *}$, Kioko Killu' ${ }^{1}$, Emmanuel Wamalwa ${ }^{6}$, Salim Sohani ${ }^{4}$, \\ Kendra Siekmans ${ }^{5}$, Andrew Nyandigisi ${ }^{2}$, Willis Akhwale ${ }^{2}$
}

From Challenges in malaria research

Basel, Switzerland. 10-12 October 2012

\section{Background information}

The success of community case management in improving access to effective malaria treatment for young children relies on broad utilization of community health workers (CHWs) to diagnose and treat fever cases. A better understanding of the factors associated with $\mathrm{CHW}$ utilization is crucial in informing national malaria control policy and strategy in Kenya. Specifically, little is known in Kenya on the extent to which CHWs are utilized, the characteristics of families who report utilizing CHWs and whether utilization is associated with improved access to prompt and effective malaria treatment. This paper examines factors associated with utilization of CHWs in improving access to malaria treatment among children under five years of age by women caregivers in two malaria endemic districts in Kenya

\section{Methods}

This study was conducted in 113 hard-to-reach and poor villages in Malindi and Lamu districts in the coastal region classified as having endemic transmission of malaria. A cross-sectional household survey was conducted using a standardized malaria indicator questionnaire at baseline $(\mathrm{n}=1,187)$ and one year later at end-line assessment $(\mathrm{n}=$ 1,374) using two-stage cluster sampling.

\section{Results}

There was an increase in reported utilization of CHWs as source of advice/treatment for child fevers from $2 \%$ at

Kenya Red Cross Society, P.O Box 40712, Nairobi 00100, Kenya ${ }^{3}$ University of Nairobi Institute of Tropical and Infectious Community Diseases (UNITID), P.O Box 30197, Nairobi 00100, Kenya

Full list of author information is available at the end of the article baseline to $35 \%$ at end-line, accompanied by a decline in care-seeking from government facilities (from $67 \%$ to $48 \%)$ and other sources (26\% to $2 \%$ ) including shops. The most poor households and poor households reported higher utilization of $\mathrm{CHWs}$ at $39.4 \%$ and $37.9 \%$

\section{Table 1}

\begin{tabular}{|c|c|c|c|}
\hline Characteristic & BASELINE & ENDLINE & P-Values \\
\hline Sample size (N) & 269 & 345 & \\
\hline Women caregiver education level & & & 0.125 \\
\hline None & $53.2(143)$ & 57.7 (199) & \\
\hline Primary & $43.5(117)$ & $41.2(142)$ & \\
\hline Secondary & $3.4(9)$ & $1.2(4)$ & \\
\hline Woman caregiver age category & & & 0.332 \\
\hline$<=20 y$ & $21.2(57)$ & $15.7(54)$ & \\
\hline $21-30 y$ & $44.6(120)$ & $47.1(162)$ & \\
\hline $31-50$ y & $26.7(72)$ & $29.4(101)$ & \\
\hline $51+y$ & & $1.1(4)$ & \\
\hline Unknown & $7.4(20)$ & $6.7(23)$ & \\
\hline Male household head & $84.1(216)$ & $81.7(282)$ & 0.285 \\
\hline Household owns radio & $40.9(105)$ & $32.8(113)$ & 0.041 \\
\hline Household owns bicycle & $56.4(145)$ & $48.1(166)$ & 0.044 \\
\hline Household owns mosquito nets & $81.3(209)$ & $89.3(308)$ & 0.006 \\
\hline Village size & & & 0.531 \\
\hline$<=60$ households & $21.9(59)$ & $18.6(64)$ & \\
\hline 61 to 100 households & $24.5(66)$ & $27.8(96)$ & \\
\hline 101 to 200 households & $31.6(85)$ & $32.2(111)$ & \\
\hline >200 households & $21.9(59)$ & $21.5(74)$ & \\
\hline Household wealth rank & & & 0.335 \\
\hline Most poor & $22.3(60)$ & $23.8(82)$ & \\
\hline Poor & $54.3(146)$ & 57.7 (199) & \\
\hline Least poor & $23.4(63)$ & $18.6(64)$ & \\
\hline
\end{tabular}


Table 2 Source of advice/treatment for children with fever in past 2 weeks among those who reported seeking advice/treatment

\begin{tabular}{lcccc}
\hline Source of advice/treatment & \multicolumn{2}{c}{$\begin{array}{c}\text { Baseline } \\
(\mathbf{N = 2 3 5 )}\end{array}$} & \multicolumn{2}{c}{$\begin{array}{c}\text { Endline } \\
(\mathbf{N}=\mathbf{2 9 8})\end{array}$} \\
\cline { 2 - 5 } & $\mathbf{n}$ & $\%$ & $\mathbf{n}$ & $\%$ \\
\hline CHW/Red Cross volunteer $^{\mathbf{1}}$ & 5 & 2.1 & 103 & 34.6 \\
Government health facilities $^{1}$ & 157 & 66.8 & 143 & 48.0 \\
Private medical sector $^{1}$ & 12 & 5.1 & 46 & 15.4 \\
Other sources $^{1}$ & 59 & 26.0 & 6 & 2.0 \\
\hline
\end{tabular}

respectively, compared to the least poor households (17.0\%). Households in villages with less than 200 households reported higher CHWs utilization as compared to households in villages having $>200$ households. Prompt access to timely and effective treatment was 5.7 times higher (95\% CI 3.4-9.7) when CHWs were the source of care sought. Adherence was high regardless of whether source was CHWs $(73.1 \%)$ or public health facility (66.7\%).
Table 4 A cross tabulation of timely provision of AL and source of the antimalarial

\begin{tabular}{lccc}
\hline Timing of AL treatment & \multicolumn{2}{c}{ CHW as source of advice/ } & \multirow{2}{*}{ p-value } \\
& treatment & \\
\cline { 2 - 3 } & Yes & No & \\
\hline AL given within 24 hours & $57.3(59)$ & $19.0(37)$ & $<0.001$ \\
AL given within 48 hours & $79.6(82)$ & $36.4(71)$ & $<0.001$ \\
AL given at any time & $90.3(93)$ & $45.1(88)$ & $<0.001$ \\
\hline
\end{tabular}

\section{Conclusion}

The results of this study provide evidence that use of trained and supervised community health workers in community case management improved management of uncomplicated child fever cases in hard to reach villages in Malindi and Lamu District in Coastal Province of Kenya. In addition to this, poverty seems to be closely linked to child caregivers seeking services of communitybased service providers, highlighting the impediment of poverty towards accessibility of cost sharing services

Table 3 Women caregiver, household and village characteristics associated with utilization of CHW services for child fever advice/treatment

\begin{tabular}{|c|c|c|c|}
\hline Characteristic & $\begin{array}{c}\text { CHW } \\
(\mathrm{N}=103)\end{array}$ & $\begin{array}{l}\text { Other } \\
(\mathrm{N}=195)\end{array}$ & p-value \\
\hline \multicolumn{4}{|l|}{ Women caregiver education } \\
\hline No formal education & $57.3(59)$ & $56.4(110)$ & 0.885 \\
\hline Primary/secondary & $42.7(44)$ & $43.6(85)$ & \\
\hline Women caregiver age group & $N=98$ & $N=178$ & \\
\hline$\leq 20$ y & $16.3(16)$ & $17.4(31)$ & 0.993 \\
\hline $21-30 y$ & $50.0(49)$ & $48.9(87)$ & \\
\hline $31-40$ y & $29.6(29)$ & $29.2(52)$ & \\
\hline $41+y$ & $4.1(4)$ & $4.5(8)$ & \\
\hline Attended ANC during last pregnancy & $\begin{array}{c}N=100 \\
69.0(69)\end{array}$ & $\begin{array}{c}N=193 \\
65.8(127)\end{array}$ & \\
\hline IPT (2+ doses SP) during last pregnancy & $\begin{array}{c}N=56 \\
82.1(46)\end{array}$ & $\begin{array}{c}N=111 \\
84.7(94)\end{array}$ & \\
\hline Knowledge of $\mathrm{AL}$ as new anti-malarial drug & & $\begin{array}{c}N=194 \\
29.9(58)\end{array}$ & \\
\hline Identified sleeping under net as way to prevent malaria & $84.5(87)$ & $78.0(152)$ & 0.179 \\
\hline \multicolumn{4}{|l|}{$\begin{array}{l}\text { Household wealth rank } \\
\text { Most poor } \\
\text { Poor } \\
\text { Least poor }\end{array}$} \\
\hline Household size & $\mathrm{N}=102$ & $\mathrm{~N}=194$ & \\
\hline 2 to 4 & $22.6(23)$ & $24.7(48)$ & 0.425 \\
\hline 5 to 7 & $41.2(42)$ & $46.4(90)$ & \\
\hline 8 or more & $36.3(37)$ & $28.9(56)$ & \\
\hline \multicolumn{4}{|l|}{$\begin{array}{l}\text { Village size } \\
<60 \text { households }\end{array}$} \\
\hline $61-100$ households & $33.0(34)$ & $24.6(48)$ & \\
\hline 101-200 households & $34.0(35)$ & $30.3(59)$ & \\
\hline$>200$ households & $10.7(11)$ & $27.7(54)$ & \\
\hline Visited by CHW in past 3 months & $94.2(97)$ & $28.7(56)$ & $<0.001$ \\
\hline
\end{tabular}


widely practiced in Kenyan public health facilities. Policy actions to address barriers to effective utilization of CHWs in healthcare delivery should be scaled up in such hard to reach communities. The government and partners should, therefore, invest more in mechanisms which support CHW utilization especially the roll out of the Community Health Strategy 2006 as part of successful control of malaria and other infectious diseases.

The potential for utilization of CHWs in improving access to malaria treatment at the community level is promising. This will not only enhance access to treatment by the poorest households but also provide early and appropriate treatment to vulnerable individuals, especially those living in hard to reach areas.

\section{Author details}

${ }^{1}$ Kenya Red Cross Society, P.O Box 40712, Nairobi 00100, Kenya. ${ }^{2}$ Ministry of Public Health and Sanitation, Kenya. ${ }^{3}$ University of Nairobi Institute of Tropical and Infectious Community Diseases (UNITID), P.O Box 30197, Nairobi 00100, Kenya. ${ }^{4}$ Canadian Red Cross, 170 Metcalfe Street, Suite 300, Ottawa, ON K2P 2P2, Canada. ${ }^{5}$ HealthBridge, 1004-1 Nicholas Street, Ottawa, ON K1N 7B7, Canada. ${ }^{6}$ Care International in Kenya, P.O. Box 43864, Nairobi 00100, Kenya.

Published: 9 November 2012

\section{Submit your next manuscript to BioMed Central} and take full advantage of:

- Convenient online submission

- Thorough peer review

- No space constraints or color figure charges

- Immediate publication on acceptance

- Inclusion in PubMed, CAS, Scopus and Google Scholar

- Research which is freely available for redistribution

Submit your manuscript at www.biomedcentral.com/submit 